\section{Four modalities of periodontal treatment compared over five} years

\author{
Ramfjord SP, Caffesse RG, Morrison EC, Hill RW, Kerry GJ, Appleberry EA, \\ Nissle RR and Stults DL: Four modalities of periodontal treatment compared \\ over five years. Journal of Periodontal Research 1987: 22: 222-223.
}

\author{
S. P. Ramfjord, R. G. Caffesse, \\ E. C. Morrison, R. W. Hill, G. J. \\ Kerry, E. A. Appleberry, R. R. Nissle \\ and D. L. Stults
}

The University of Michigan School of Dentistry, Ann Arbor, Michigan, U.S.A.
The purpose of the study was to compare, over $5 \mathrm{yr}$, the results following four conventionally used modalities of treatment for moderate-to-advanced periodontitis. Ninety subjects (53 females and 37 males), age 24 to $68 \mathrm{yr}$ (mean 45) were selected for the study from persons seeking dental care or who were referred for periodontal treatment at The University of Michigan School of Dentistry. To be included, the subjects had to have at least 20 treatable teeth, and some periodontal pockets extending at least $4.0 \mathrm{~mm}$ or more apically to the cementoenamel junction. Plaque, gingivitis, calculus, depth of pockets, clinical loss of attachment from the cementoenamel junction and tooth mobility were scored. For the present paper, only pocket depth and attachment level scores were considered. All of the patients then had scaling, root planing and instruction in oral hygiene by a dental hygienist for a total of 5 to 8 h over about 4 wk.

A periodontist checked the completeness of calculus removal and did occlusal adjustment if he considered it to be indicated

A rescoring was done $4 \mathrm{wk}$ after completion of the scaling and root planing. Then four types of periodontal treatment were provided by a periodontist. Each quadrant of the patient's dentition was assigned randomly to one of four treatment types: (1) surgical pocket elimination or reduction, including bone surgery, (2) modified Widman flap surgery, (3) subgingival curettage following scaling and root planing, and (4) scaling and root planing only.

The teeth were polished once a week for 3 to $4 \mathrm{wk}$ after the periodontal treatment. Then the patients were placed on recall prophylaxis and topical fluoride every 3 months, and scored annually prior to prophylaxis. If, at the time of the routine prophylaxis, pocket exudate could be expressed by moving a ball burnisher against the surface of the gingiva and/or overt bleeding resulted from pocket probing, the patient was rescheduled in 2 to $3 \mathrm{wk}$ for examination and possible retreatment by a periodontist.

Data for pocket depth and attachment level were arranged on the basis of the initial measurements in groups of 1-3 $\mathrm{mm}$ depth, 4-6 $\mathrm{mm}$ and $\geq 7 \mathrm{~mm}$ depth. One-way analysis of variance was used to test the hypothesis of equal treatment effects in the three levels of pocket depth at the end of the hygienic phase and at each yearly interval following treatment. The test was performed on patient means for changes in pocket depth and attachment level. If the hypothesis of equal treatment effect was rejected at the 0.05 level of significance using ANOVA, Scheffe's method for multiple comparisons was used to determine which of the pairs of treatment differed. Percentage distribution of sites with loss of $\geq 2 \mathrm{~mm}$ and $\geq 3 \mathrm{~mm}$ for the various groups also were compared. The measurements for the teeth that were lost were included until the teeth were lost. Seventy-two of the original 90 patients completed the 5-yr study.

\section{Summary of findings}

The tables with detailed measurements will be published in a separate paper so that a summary of the results is given here.

The variations in crevice depth after treatment in crevices 1-3 $\mathrm{mm}$ were small, and not significant over the 5 yr. A slight deepening of the crevices occurred gradually for all modalities of treatment. There was, however, a grad- ual loss of attachment over the $5 \mathrm{yr}$ for the $1-3 \mathrm{~mm}$ crevices. The scaling and root planing and the curettage groups showed significantly less loss than the surgery groups, but the differences were small.

The 4-6 $\mathrm{mm}$ pockets were reduced significantly in depth from baseline. The greatest reduction was following pocket elimination surgery, but the differences were small. The attachment level responses were most favorable after scaling and root planing and after curettage, with no significant difference between these two methods.

For the deep pockets ( $\geq 7 \mathrm{~mm}$ ), there was a considerable reduction in pocket depth after the initial hygienic phase. One year after periodontal treatment, the greatest reduction was after pocket elimination or reduction surgery, but after 5 yr the differences were not significant.

The sites with pocket depth of 1-3 $\mathrm{mm}$ at baseline had the highest frequency of attachment loss both for $\geq 2$ $\mathrm{mm}$ and for $\geq 3 \mathrm{~mm}$, and a higher frequency of attachment loss for surgical procedures than for either curettage or scaling and root planing. For sites 4-6 $\mathrm{mm}$ deep with a variation of $\geq 2 \mathrm{~mm}$, scaling and root planing had a higher percentage of attachment gains than did any of the other procedures. For the deeper pockets $\geq 7 \mathrm{~mm}$, more sites gained than lost attachment, but the differences between procedures were minimal.

In the 72 patients who completed the 5 -yr course of treatment, 22 teeth were lost. Of those, 17 were lost for periodontal reasons, and 16 of those had furcation involvement before treatment. One hundred and one teeth were retreated during the maintenance phase, and almost half of these teeth had orig- 
inally been treated with scaling and root planing only. Only 2 of the retreated teeth were lost.

\section{Conclusions}

1. Scaling and root planing alone was as effective in maintenance of clinical periodontal attachment as curettage for pockets $\leq 6 \mathrm{~mm}$, and preferable to the other surgical modalities of treatment.

2. For pockets $\geq 7 \mathrm{~mm}$ the attachment results were similar for the four methods.

3. Selective retreatment during the maintenance phase appears to be desirable.
Address:

S. P. Ramfjord

The University of Michigan School of Dentistry

Ann Arbor

Michigan

U.S.A. 
This document is a scanned copy of a printed document. No warranty is given about the accuracy of the copy. Users should refer to the original published version of the material. 